\title{
Clarifying Bibliographical Citation
}

\author{
Mr. Postell is librarian of the School of \\ Medicine of the Louisiana State University, \\ at New Orleans.
}

$\mathrm{T}$ HE LITERATURE regarding the principles of bibliographical citation is quite extensive, and it is not the purpose of this paper to repeat what has already been stated but to make an attempt to clarify some of the precepts regarding this very important problem.

It has been very puzzling at times to know how to advise students, internes, residents, and younger faculty members who come for advice on how to arrange references or bibliographies for papers they are preparing for publication. It is not always so simple to apply the often repeated maxim to follow the form required by the journal to which it is planned to submit the paper. In many cases the journals themselves are not too consistent in their bibliographical citations.

Briefly, the purpose of bibliographical citation is to give authority for every statement or fact quoted and also to provide a clear and concise description of the document from which each statement it taken. The reason' for this is that a citation is an integral part of the logic. It is a link in the chain of evidence, and its source should be so clearly given that no one would have any trouble in verifying a statement.

Undoubtedly the clearest explanation of the principles of bibliographical citation was outlined by J. F. Fulton ${ }^{1}$ in his excellent paper on this very subject. Anyone who fol-

1 Fulton, J. F. "The Principles of Bibliographical
Citation." Citation." Bulletin of the
tion 22:183-97, April 1934.

JUNE, 1945 lows the precepts laid down by Dr. Fulton cannot go wrong, but generally medical and scientific journals have adopted modifications of these principles which have proved somewhat puzzling. In many cases there seems to be a lack of clear understanding as to the meaning of "bibliography," "references," or "literature cited." These terms are used interchangeably, with little regard as to their proper meaning.

A bibliography is generally recognized as a compilation of the literature of a given subject. It is comprehensive in scope and is arranged or should be arranged alphabetically by author and appended at the end of the paper. On the other hand, the terms "literature cited" or "references" usually refer to a specific statement or fact and are arranged in the order in which the references are cited. These citations may either be placed as footnotes or appended at the end of an article.

For the sake of clarity and in order to have some basis or criteria for advising students as to the form and arrangement of their references or bibliographies, it was decided arbitrarily to divide medical and scientific publications into three groups. To each group is assigned a recommended form for the arrangement of its citations.

Group one includes those papers which as a rule are short and deal with one specific topic. In this type of article there is usually very little general information or what may be referred to as background material; the references generally are to one particular statement or fact. For these papers it is (Continued on page 288) 
Manuscript Collections in the William L. Clements Library, A Guide to the Manuscript Collections in the Archives of the North Carolina Historical Commission, A Guide to the Personal Papers in the Manuscript Collections in the Minnesota Historical Society, and The American Manuscript Collections in the Huntington Library.

To historical students it is at times shocking to learn that material greatly needed has been destroyed or is hidden away in some unappreciative person's storage spaces. For example, to the Western Reserve Historical Society there came not long ago the full records of an interesting but defunct uni- versity in Ohio for the years 1834-47. They had been resting in a box of family relics all these years, a curiosity for the owner but unavailable for any serious uses. Whatever will help to enlighten the people of the United States on the usefulness of the papers in private homes and public archives is a national service of great value for the future. The librarians, curators, and directors of some eight hundred historical societies have an ever-present challenge. They have the chance for a mass attack on apathy and ignorance which ought to bear good fruit.-Elbert $J$. Benton, director and secretary, Western Reserve Historical Society, Cleveland.

\section{Clarifying Bibliographical Citation}

\section{(Continued from page 249)}

recommended that the citations be arranged in the order in which they are referred or quoted from and appended at the end of the paper. Each reference should be a complete bibliographical citation, e.g., author, title, journal, volume, pagination, month, year. This is the form used by the journals published by the American Medical Association.

To group two is assigned the papers of some length, including monographs and papers published in review journals. Such papers present a comprehensive study of a given subject, including its history and an outline of the experimental work accomplished. These articles contain a considerable amount of general information as well as references to a specific statement. In these cases it is recommended that citations be labeled "bibliography," arranged alphabetically by author, and numbered and appended at the end of the article. Throughout the paper, whenever it becomes necessary to refer to a citation, the number of the reference simply may be listed following the statement. In those cases where it becomes necessary to refer to a specific page in a citation, the number of the page may follow the number of the reference. As an example of the use of this type of citation refer to the monograph by T. E. Keys. ${ }^{2}$

To the third group is assigned papers of such a general nature as to make reference to any one bibliographical item unnecessary. To these papers it is recommended that the bibliography be alphabetically arranged by author and appended at the end of the article.

This classification has simplified the interpretation of the principles of bibliographical citation to a marked degree and has also served as a logical explanation in explaining the different forms to the students.

${ }^{2}$ Keys, T. E. The Development of Anesthesia, n.d.
78 p. 